\title{
Neutral lipid storage disease
}

INSERM

\section{Source}

INSERM. (1999). Orphanet: an online rare disease and orphan drug data base. Neutral lipid storage disease. ORPHA:165

Neutral lipid storage disease (NLSD) refers to a group of diseases characterized by a deficit in the degradation of cytoplasmic triglycerides and their accumulation in cytoplasmic lipid vacuoles in most tissues of the body. The group is heterogeneous: currently cases of NLSD with icthyosis (NLSDI/Dorfman-Chanarin disease; see this term) and NLSD with myopathy (NLSDM/neutral lipid storage myopathy; see this term) can be distinguished. 